\title{
Response of Bosmina size structure to the acidification and recovery of lakes near Sudbury, Canada
}

\author{
Andrew L. LABAJ, ${ }^{1 *}$ Jennifer B. KOROSI, ${ }^{2}$ Joshua KUREK, ${ }^{3}$ Adam JEZIORSKI, ${ }^{1}$ Wendel (Bill) KELLER, ${ }^{4}$ John P. SMOL ${ }^{1}$ \\ ${ }^{1}$ Paleoecological Environmental Assessment and Research Laboratory (PEARL), Department of Biology, Queen's University, Kingston, \\ ON, K7L 3N6, Canada; ${ }^{2}$ Department of Biology, University of Ottawa, 30 Marie Curie Pvt., Ottawa, ON, K1N 6N5, Canada; ${ }^{3}$ Department \\ of Geography and Environment, Mount Allison University, Avard-Dixon Building, 144 Main St., Sackville, NB, E4L 1A7, Canada; \\ ${ }^{4}$ Living with Lakes Centre, Laurentian University, 935 Ramsey Lake Rd., Sudbury, ON, P3E 2C6, Canada \\ *Corresponding author: a.labaj@queensu.ca
}

\begin{abstract}
In response to biotic and abiotic cues, the cladoceran genus Bosmina can undergo changes in body size and appendage length and shape over successive generations. To improve our understanding of the environmental controls on Bosmina size structure, we used paleolimnological techniques to examine Bosmina size responses to the extreme acidification and metal contamination, and then subsequent chemical recovery, of lakes in the vicinity of mining and smelting operations near Sudbury, Canada. During the acidification period, Bosmina antennule and carapace length significantly increased in three of the five study lakes, while mucro length significantly decreased in four of the five lakes. However, despite the recent return to pre-impact $\mathrm{pH}$ levels, the size structure of the present-day Bosmina community still differs from the pre-impact size distributions. We suggest that the continued dominance of the food webs by small invertebrate predators (e.g., cyclopoid copepods) is responsible for the persistent changes to Bosmina size structure.
\end{abstract}

Key words: Cladocera; Bosmina; paleolimnology; multiple-stressors; industrial contamination.

Received: February 2015. Accepted: June 2015.

\section{INTRODUCTION}

The Cladocera are a widespread order of crustacean zooplankton that occupy an intermediate trophic position in aquatic food webs. Many cladoceran taxa undergo cyclomorphosis, altering body size and morphology in response to environmental stimuli over successive generations. The influence of invertebrate predation on cladoceran cyclomorphosis has been well-studied, with invertebrate predators inducing an increase in body size and the development of defensive structures such as neck teeth in Daphnia (Hebert and Grewe, 1985; Black, 1993) and elongated mucros and antennules in Bosmina (Kerfoot, 1975; Black, 1980). However, other environmental factors also affect cladoceran size structure, including temperature (Coker, 1939; Brooks, 1946; Hebert, 1978; Kappes and Sinsch, 2002), food availability (Hebert, 1978), and $\mathrm{pH}$ (Locke and Sprules, 2000; Korosi et al., 2008). Size structure is an important attribute of zooplankton ecology, influencing algal grazing rates (larger-sized animals tend to be more efficient grazers; DeMott, 1982; Tóth and Kato, 1997), fitness, competitive abilities, and energy transfer up the food web (Lynch, 1977; Hart and Bychek, 2011). As cladocerans are often both the primary algal grazers and the principal prey items for planktivorous fish and invertebrate predators in many aquatic food webs, changes to cladoceran size structure can also impact trophic dynamics.
Bosmina, a herbivorous filter-feeding cladoceran genus, is one of the most common pelagic invertebrates in temperate lakes of North America. In response to predation and environmental conditions, cyclomorphosis in Bosmina manifests as changes in carapace size and the length and shape of the antennules and mucros (Kerfoot, 1975; Black, 1980). These shifts are most often linked to predation by invertebrate predators such as Chaoborus and copepods (Kerfoot, 1975; Black, 1980; Post et al., 1995; Korosi et al., 2013), rather than population age structure, as antennules and mucros change little throughout the life of an individual animal (Deevey and Deevey, 1971). When the risk of injury by a predator outweighs the risk of mortality (e.g., attacks from small invertebrates such as copepods), longer antennule lengths may confer protection from damage by curving over the vulnerable swimming appendages, shielding them from damage in an attack (Kerfoot, 1975; Post et al., 1995). When mortality risk is high (e.g., predation by larger invertebrates such as Chaoborus), longer mucros and increased carapace size increase prey-handling time and decrease the success rate of attacks (Black, 1980; Sprules et al., 1984; Post et al., 1995; Korosi et al., 2013). In the presence of visual predators such as planktivorous fish, smaller size attributes may be beneficial to reduce visibility to these predators, which often selectively prey upon larger individuals (Kerfoot, 1975; Nilssen and Sandøy, 1990). 
Abiotic factors may also impact Bosmina size structure; notably, acidification has been associated with shifts in antennule and carapace length (Locke and Sprules, 2000; Korosi et al., 2008). However, reported changes in size structure associated with lake acidification have not been consistent. In some cases, acidification was associated with decreases in Bosmina body size (Locke and Sprules, 1993, 2000; Korosi et al., 2008), while others observed increases in body size and appendage length (Nilssen and Sandøy, 1990). Acidification not only impacts organisms through direct physiological mechanisms, but can also alter food webs and predation regimes, which may account for these discrepancies. For example, as lakes acidify and fish are extirpated, Chaoborus often becomes the dominant predator of zooplankton (Yan et al., 1991) and these changes in the predation regime may alter zooplankton community composition and size structure. Therefore, the mechanisms affecting size structure, whether direct physiological stress or changes in predation, remain unclear.

Long-term perspectives are required to relate changes in size structure with known environmental stressors at both local and regional scales. Bosmina leave abundant, identifiable remains in lake sediments, allowing changes in size structure through time to be tracked using paleolimnological techniques (Korhola and Rautio, 2001; Korosi et al., 2013; Labaj et al., 2013). Furthermore, paleolimnological methods are ideal for assessing the response of Bosmina to acidification, allowing long-term (i.e., from pre-impact times to the present-day) trends in size structure to be examined. As lake sediments integrate organisms across whole-lake environments, incorporating seasonal and inter-annual variability, they can provide a holistic view of biotic shifts through time. In a top-bottom (i.e., pre-impact to present-day comparison) paleolimnological survey of 44 softwater Ontario lakes located around Dorset, Ontario, Canada ( 200 km SE of Sudbury), Korosi et al. (2010) noted decreased antennule and mucro lengths in Bosmina, and decreased postabdominal claw lengths in Daphnia spp. in modern times, compared to specimens collected from pre-industrial sediments. The differences in size were attributed to decreased copepod predation, as well as moderate acidification that occurred in the region (Korosi et al., 2010). However, since only two sediment samples are analysed when using a top-bottom paleolimnological approach, this procedure does not allow for the timing of size changes to be linked with the onset of individual stressors.

We use a paleolimnological approach to assess the response of Bosmina size structure to severe acidification, metal contamination, and the subsequent chemical recovery of five intensively studied Boreal Shield lakes through time in the vicinity of Sudbury, Ontario. Previously, Labaj et al. (2015) documented the cladoceran species assem- blage changes that had occurred in these lakes as a response to anthropogenic stressors. Here, we compare Bosmina size attributes from the pre-impact, acidification/metal contamination, and recovery periods to address the hypothesis that Bosmina size structure changed in response to acidification and/or metal contamination. We predicted that: i) If the Bosmina size structure changes are primarily a response to metal contamination, size differences will be more pronounced in lakes that were acidified and contaminated with heavy metals, relative to those that only acidified; ii) If Bosmina size responds to acidification through direct physiological impacts, body size should decrease during the period of acidification, and increase again following recovery of $\mathrm{pH}$; and iii) If Bosmina size is responding indirectly to acidification through changes in predator assemblages, size changes between lakes will reflect a shift in the dominant predators.

\section{METHODS}

\section{Site description and field methods}

Lakes near Sudbury (Ontario, Canada) experienced severe acidification and contamination with copper and nickel due to emissions from nearby smelting operations that began in the late-1800s (Gunn, 1996). At the peak of industrial emissions in the 1960s, many lakes within $\mathrm{a} \sim 17,000 \mathrm{~km}^{2}$ region acidified, with the $\mathrm{pH}$ of circumneutral lakes declining to as low 4 (Neary et al., 1990; Gunn, 1996).

Three of the study lakes (Daisy, Middle, Clearwater) are located within the city limits of Sudbury. The lakes were heavily acidified by the 1970 s (to $\mathrm{pH}<5$; Keller et al., 2004) and have aqueous $\mathrm{Cu}$ and $\mathrm{Ni}$ concentrations that continue to exceed provincial water quality guidelines (Cooperative Freshwater Ecology Unit, Laurentian University, 2013). Each of the three Sudbury study lakes has undergone prior diatom-based reconstructions of $\mathrm{pH}$ (Dixit et al., 1987, 1990, 1996), analyses of sedimentary metals (Snetsinger, 1993; Tropea, 2008; Tropea et al., 2010), cladoceran assemblages and sedimentary chlorophyll-a (Labaj et al., 2015), and regular water chemistry monitoring since 1973 (Middle, Clearwater) or 1991 (Daisy; Cooperative Freshwater Ecology Unit, Laurentian University, 2013).

Lumsden and George lakes are situated in Killarney Provincial Park, $\sim 60 \mathrm{~km}$ southwest of Sudbury. Although lakes in Killarney generally acidified to a similar level as lakes in the immediate vicinity of Sudbury, they experienced lower inputs of $\mathrm{Cu}$ and $\mathrm{Ni}$ due to their greater distance from the smelters (Yan and Strus, 1980; Labaj et al., 2015). Both Killarney lakes have also been examined in paleolimnological reconstructions of $\mathrm{pH}$ (Dixit et al., 1992), cladocerans and chlorophyll- $a$ (Labaj et al., 2015), sedimentary metals (Snetsinger, 1993), and water chem- 
istry monitoring since 1981 (George) and 1998 (Lumsden; Cooperative Freshwater Ecology Unit, Laurentian University, 2013).

Sediment cores were collected from each lake in July 2012 using a Glew (1989) gravity corer, and sectioned on shore using a Glew (1988) extruder. Sediments were sectioned at $0.25-\mathrm{cm}$ resolution from 0 to $15 \mathrm{~cm}$, and at 0.5 $\mathrm{cm}$ resolution for the remainder of the core. Sediments were stored in a cooler with cold packs until transportation to the laboratory. Only the surface $(0-0.25 \mathrm{~cm})$ sediments of the 2012 Daisy Lake core were analysed (representing the year 2012), with the remainder of the sediments sourced from a dated core previously analysed for sedimentary metals (Tropea, 2008; Tropea et al., 2010). The 2012 surface sediments allowed the most recent cladoceran assemblage of Daisy Lake to be assessed (Labaj et al., 2015), without the need to establish a ${ }^{210} \mathrm{~Pb}-$ based chronology from a second core from the lake. The cores were collected from locations as close as possible to each other within Daisy Lake. Due to the widespread $\left(\sim 17,000 \mathrm{~km}^{2}\right.$ area $)$ acidification surrounding Sudbury, locating an unimpacted control lake in the immediate region is not feasible. Nonetheless, our use of the paleolimnological approach allows pre-impact conditions to be assessed and compared with impacted and recovery periods.

\section{Laboratory methods}

Sediment dates were established with gamma spectroscopy using ${ }^{210} \mathrm{~Pb}$ chronologies, and the constant rate of supply (CRS) method described by Appleby (2001). Sediment ages beyond background ${ }^{210} \mathrm{~Pb}$ levels were extrapolated using a second-order polynomial function fit to the established dating curve (Labaj et al., 2015). Sample processing largely followed methods outlined in Korhola and Rautio (2001). Briefly, sediment samples were deflocculated in $10 \% \mathrm{KOH}$ solution on a hotplate for 20 minutes, then collected on a $38 \mu \mathrm{m}$ mesh sieve, and mounted on glass slides with glycerine jelly. Bosmina sizes were measured at 200x magnification on a Leica DMR light microscope. All identifiable and intact Bosmina remains were digitally photographed, and measured using Northern Eclipse imaging software (Empix Imaging, Inc.). A minimum of 40 headshields, mucros, and carapaces were measured to ensure variation was captured in the assemblage (Brahney et al., 2010). Bosmina were classified as either Bosmina spp. or Eubosmina spp., based on the arrangement of pores on the headshields.

\section{Data analysis methods}

To assess the impacts of acidification on Bosmina size attributes, the history of each study lake was divided into three periods: pre-impact (from $\sim 1800$ to the beginning of $\mathrm{pH}$ decline; Tab. 1), acidification (period of lowest $\mathrm{pH}$; Tab. 1), and recovery (time that $\mathrm{pH} \geq$ background levels to present), based on previously published diatom-inferred $\mathrm{pH}$ profiles and monitoring data for the study lakes (Dixit et al., 1987, 1990, 1992, 1996; Cooperative Freshwater Ecology Unit, Laurentian University, 2013; Tab. 1). Due to differences in acidification trends in each lake, the number of samples from each period differed between lakes (Tab. 1). A nonparametric Kruskal-Wallis test was used to assess whether distribution of each size attribute differed across the time periods. Pairwise Mann-Whitney U-tests (with Holm corrections applied to P-values) were used to assess significance $(\mathrm{P}<0.05)$ of shifts in distribution between pre-impact, acidification, and recovery periods.

Tab. 1. Time periods in each of the 5 study lakes, based on diatom-inferred $\mathrm{pH}$ (Dixit et al., 1987, 1990, 1992, 1996) and pH monitoring (Cooperative Freshwater Ecology Unit, Laurentian University, 2013).

\begin{tabular}{|c|c|c|c|c|c|}
\hline Lake & Period & pH during period & Number of intervals & $\begin{array}{l}\text { Sediment interval } \\
\text { midpoints }(\mathrm{cm})\end{array}$ & $\begin{array}{c}\text { Approximate dates } \\
\text { of period }\end{array}$ \\
\hline Daisy & $\begin{array}{l}\text { Pre-impact } \\
\text { Acidification } \\
\text { Recovery }\end{array}$ & $\begin{array}{l}>6 \\
<5 \\
>6\end{array}$ & $\begin{array}{l}6 \\
1 \\
2\end{array}$ & $\begin{array}{c}9.13-4.63 \\
2.13 \\
0.13-\text { Surface }\end{array}$ & $\begin{array}{l}1800-1952 \\
1987-1992 \\
1999-2012\end{array}$ \\
\hline Middle & $\begin{array}{l}\text { Pre-impact } \\
\text { Acidification } \\
\text { Recovery }\end{array}$ & $\begin{array}{l}>5.8 \\
<5.5 \\
>5.8\end{array}$ & $\begin{array}{c}7 \\
1 \\
11\end{array}$ & $\begin{array}{c}16.25-7.63 \\
4.63 \\
4.13-0.13\end{array}$ & $\begin{array}{l}1800-1940 \\
1966-1972 \\
1975-2012\end{array}$ \\
\hline Clearwater & $\begin{array}{l}\text { Pre-impact } \\
\text { Acidification } \\
\text { Recovery }\end{array}$ & $\begin{array}{c}>5.8 \\
<5 \\
>5.8\end{array}$ & $\begin{array}{l}5 \\
3 \\
4\end{array}$ & $\begin{array}{l}9.63-5.63 \\
3.63-2.13 \\
1.63-0.13\end{array}$ & $\begin{array}{l}1800-1930 \\
1964-1992 \\
1997-2012\end{array}$ \\
\hline George & $\begin{array}{l}\text { Pre-impact } \\
\text { Acidification } \\
\text { Recovery }\end{array}$ & $\begin{array}{l}>5.8 \\
<5.5 \\
>5.8\end{array}$ & $\begin{array}{l}5 \\
3 \\
7\end{array}$ & $\begin{array}{c}16.25-9.13 \\
6.13-4.63 \\
3.13-0.13\end{array}$ & $\begin{array}{l}1800-1919 \\
1958-1986 \\
1993-2012\end{array}$ \\
\hline Lumsden & $\begin{array}{l}\text { Pre-impact } \\
\text { Acidification } \\
\text { Recovery }\end{array}$ & $\begin{array}{c}>5.3 \\
<5 \\
>5.3\end{array}$ & $\begin{array}{l}9 \\
1 \\
2\end{array}$ & $\begin{array}{c}20.25-7.63 \\
4.63 \\
1.13-0.13\end{array}$ & $\begin{array}{l}1800-1958 \\
1973-1983 \\
2004-2012\end{array}$ \\
\hline
\end{tabular}




\section{RESULTS}

Bosmina spp. was the dominant bosminid taxon present in Middle, Clearwater, Daisy, and Lumsden lakes (with only one Eubosmina spp. headshield found in Middle Lake). Within George Lake, Eubosmina spp. appeared in the $1930 \mathrm{~s}$, and increased to $\sim 50 \%$ of the identifiable species by 2012. Pre-impact Bosmina size attributes were variable between the study lakes, with median mucro sizes ranging from 44-65.5 $\mu \mathrm{m}$ (Fig. 1), antennules from 88.5-118.5 $\mu \mathrm{m}$ (Fig. 2), and carapaces from 193-222.5 $\mu \mathrm{m}$ (Fig. 3).

Mean shifts in distribution as identified by KruskalWallis tests occurred between time periods within all lakes and size attributes $(\mathrm{P}<0.05)$, with the exception of Lumsden Lake antennule and carapace length $(\mathrm{P}=0.90$ and 0.10 , respectively). Between the background and acidification periods, mucro length declined significantly in Daisy, Middle, Clearwater, and George lakes (Fig. 1), while antennule and carapace lengths increased significantly in Middle, Clearwater, and George lakes (Figs. 2 and 3).

From the acidification to recovery period, mucro length increased significantly in George Lake (a return towards

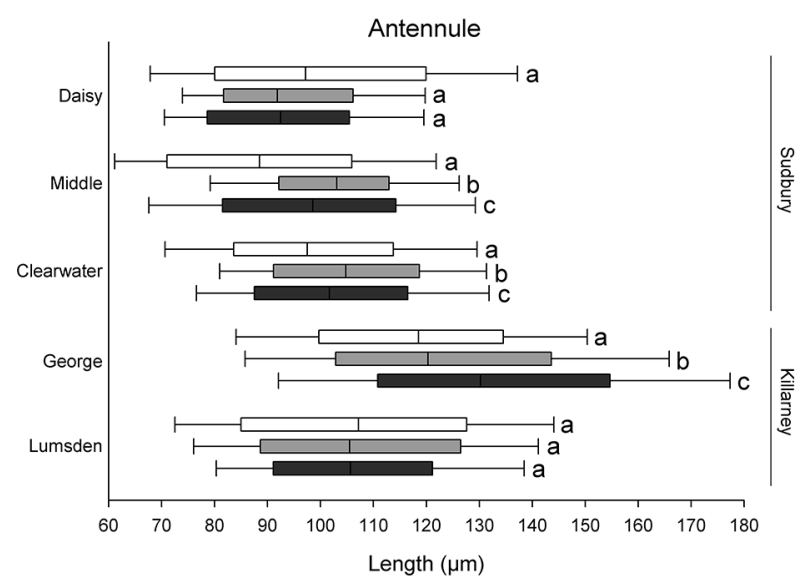

Fig. 2. Antennule lengths during pre-impact (white boxes), acidification (light gray boxes), and recovery (dark gray boxes) periods in the lakes' histories. Whiskers encompass the $10^{\text {th }}$ and $90^{\text {th }}$ percentile, and the box encompasses the $25^{\text {th }}$ and $75^{\text {th }}$ percentile. The line indicates the median. Boxes with different letters indicate periods that are significantly different from each other (within each lake), as assessed by pairwise Mann-Whitney $\mathrm{U}$-tests (significance of $\mathrm{P}<0.05$ ).

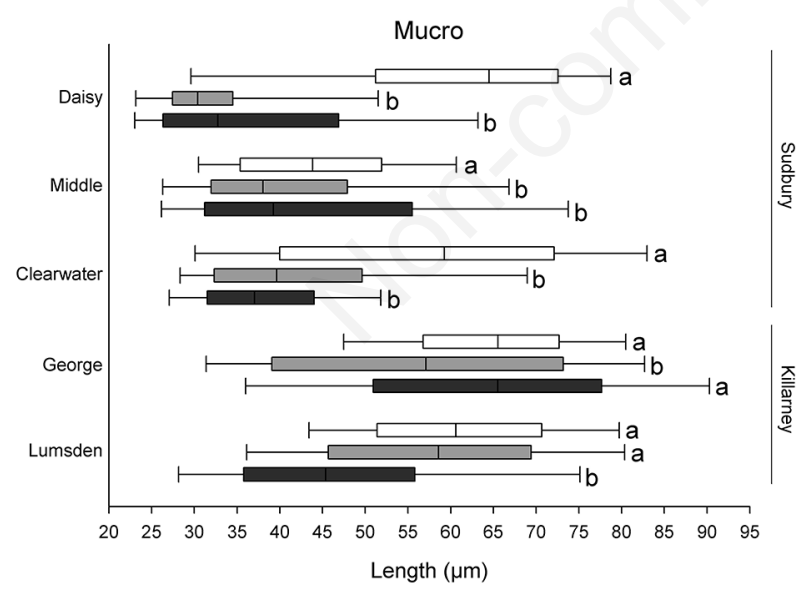

Fig. 1. Mucro lengths during pre-impact (white boxes), acidification (light gray boxes), and recovery (dark gray boxes) periods in the lakes' histories. Whiskers encompass the $10^{\text {th }}$ and $90^{\text {th }}$ percentile, and the box encompasses the $25^{\text {th }}$ and $75^{\text {th }}$ percentile. The line indicates the median. Boxes with different letters indicate periods that are significantly different from each other (within each lake), as assessed by pairwise Mann-Whitney Utests (significance of $\mathrm{P}<0.05$ ).

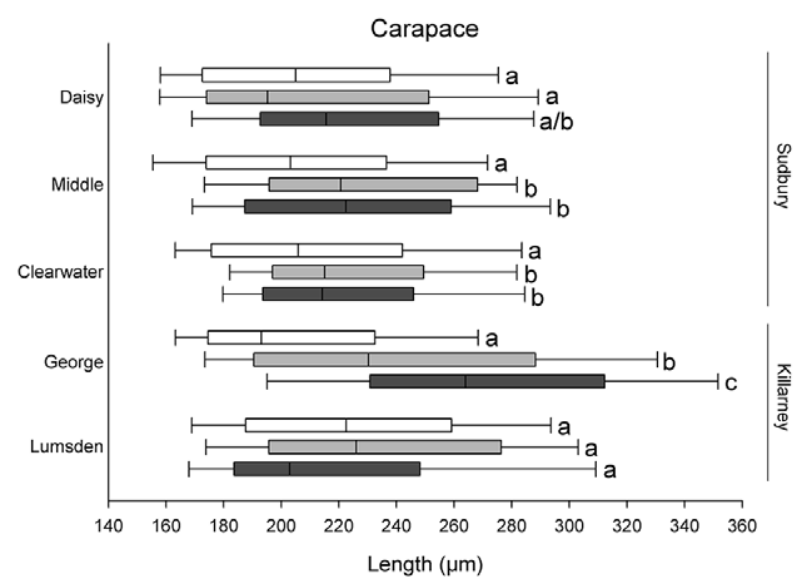

Fig. 3. Carapace lengths during pre-impact (white boxes), acidification (light gray boxes), and recovery (dark gray boxes) periods in the lakes' histories. Whiskers encompass the $10^{\text {th }}$ and $90^{\text {th }}$ percentile, and the box encompasses the $25^{\text {th }}$ and $75^{\text {th }}$ percentile. The line indicates the median. Boxes with different letters indicate periods that are significantly different from each other (within each lake), as assessed by pairwise Mann-Whitney $\mathrm{U}$-tests (significance of $\mathrm{P}<0.05$ ). Daisy Lake carapace length differed significantly between background and recovery periods $(\mathrm{P}=0.04)$, but not between background and acidification $(\mathrm{P}=0.93)$ or acidification and recovery periods $(\mathrm{P}=0.25)$. 
pre-impact size distributions), and decreased significantly in Lumsden Lake (moving further from their pre-impact distributions; Fig. 1). Antennule length decreased significantly in Middle and Clearwater lakes (towards pre-impact size distributions), and increased significantly in George Lake (moving further from pre-impact distributions; Fig. 2). Carapace length increased significantly in George Lake from the acidification to recovery period (moving further from pre-impact distributions; Fig 3).

\section{DISCUSSION}

We hypothesized that acidification and metal contamination in the Sudbury and Killarney study lakes would alter Bosmina size structure. Prior to the onset of anthropogenic disturbances, Bosmina size attributes were variable, reflecting the diversity present in food web composition (e.g., competitor species, planktivorous fish, invertebrate predators; Labaj et al., 2015; Figs. 1-3). During the period of acidification and metal contamination, we noted significant directional shifts in Bosmina size structure that were consistent among many of the study lakes (Figs. 1-3), suggesting that acidification and/or metal contamination influenced size structure either through direct physiological effects, or indirectly by transforming food webs. The bosminid assemblage in most of our lakes was dominated by Bosmina spp., however in George Lake, Eubosmina spp. began increasing in relative abundance during the acidification period, and comprised $\sim 50 \%$ of the bosminids by 2012 (Labaj et al., 2015). Replacement of Bosmina spp. by Eubosmina spp. may confound identification of the effects of acidification on bosminid size structure, as Eubosmina tend to be larger than Bosmina (Post et al., 1995). Therefore the increased abundance of Eubosmina spp. in George Lake during the acidification and recovery periods may be responsible for the larger Bosmina size attributes observed in George Lake, especially in the recovery period.

Our lakes differed in severity of contamination, and we predicted that, if Bosmina size structure was impacted by metal contamination, shifts in size structure would be most pronounced in the highly metal-contaminated Sudbury lakes (Daisy, Middle, and Clearwater) compared to those in Killarney (Lumsden and George). Long-term exposure to elevated $\mathrm{Cu}$ levels can reduce growth rate in Bosmina (Koivisto et al., 1992), and similarly, $\mathrm{Cu}$ and $\mathrm{Ni}$ exposure can reduce growth rate in the cladoceran genus Daphnia (Ingersoll and Winner, 1982; Münzinger, 1990), leading to smaller individuals at maturity. Contamination with $\mathrm{Cu}$ and $\mathrm{Ni}$ has previously been identified as an important factor structuring the cladoceran species assemblages in these lakes, with assemblages experiencing more pronounced shifts in Sudbury lakes, relative to those in Killarney (Labaj et al., 2015). However, many of the
Bosmina size attributes in Sudbury and Killarney showed shifts of similar magnitude and direction, despite different levels of metal contamination. Furthermore, increased carapace size (Fig. 3) in response to acidification and metal contamination of the study lakes contrasts with reports of reduced cladoceran body size with metal contamination elsewhere (Ingersoll and Winner, 1982; Münzinger, 1990; Koivisto et al., 1992). We further predicted that, if Bosmina was responding directly to $\mathrm{pH}$, sizes would decrease with acidification, and return to preimpact levels following recovery of $\mathrm{pH}$. However, despite recovery of $\mathrm{pH}$, size structure did not return to pre-impact levels. Moreover, the increases in size of antennules and carapaces (Figs. 2 and 3 ) with acidification differ with results of studies that report smaller Bosmina size attributes in low-pH lakes (Locke and Sprules, 2000; Korosi et al., 2008). We therefore suggest that direct physiological effects of metal contamination and low $\mathrm{pH}$ were not the main drivers of Bosmina size structure in these systems.

Acidification often precipitates major shifts in the structure and function of aquatic food webs (Appelberg et al., 1993). In the Sudbury region, acidification caused widespread loss of fish (Beamish and Harvey, 1972), as well as a shift toward acid-tolerant invertebrate predators (Yan et al., 1991). Changes to food web structure and predation regime are likely dominant factors shifting cladoceran (Locke and Sprules, 1993), and specifically Bosmina, size structure in acidified lakes (Nilssen and Sandøy, 1990; Korosi et al., 2008). We predicted that if Bosmina size structure was responding indirectly to acidification (i.e., through changes in predator assemblages), then size attributes would reflect a shift in the dominant predation regime. The increased antennule and carapace length (Figs. 2 and 3) in many of the lakes during the acidification period suggests that invertebrate predation was more intense during this time (Kerfoot, 1975; Post et al., 1995). However, mucro length, often considered the size attribute most sensitive to invertebrate predation (Sprules et al., 1984; Post et al., 1995; Labaj et al., 2014, 2015), declined in our lakes as they acidified (Fig. 1). Shifts in mucro length often occur in response to predation regime; for example, increasing in response to predation from larger invertebrate predators (e.g., Chaoborus, large copepods), as this increases prey-handling time (Kerfoot, 1975; Black, 1980; Post et al., 1995). However, elongated features carry a physiological cost, namely increasing drag, and reducing feeding rate (Lagergren et al., 1997), favouring smaller features when elongated features are not beneficial. Our results may indicate a shift from large invertebrate predators (capable of causing outright mortality) to smaller invertebrate predators, capable of damaging swimming appendages (e.g., cyclopoid copepods), as longer antennules may protect swimming appendages under attack (Post et al., 1995). Similarly, increased cara- 
pace length likely reduces overall risk of mortality from small gape-limited invertebrate predators (Korosi et al., 2013). Small, acid-tolerant cyclopoid copepods can become dominant invertebrate predators under acidified conditions (Locke and Sprules, 1993), however their abundance may also increase with increasing $\mathrm{pH}$ (Valois et al., 2010, 2011). Moreover, cyclopoid abundance has increased in Middle Lake (Yan et al., 2004) and Daisy and Clearwater lakes (Cooperative Freshwater Ecology Unit, unpublished) in the past 40 years, concurrent with $\mathrm{pH}$ improvements. The decrease in mucro length (Fig. 1) and increases in antennule and carapace length (Figs. 2 and 3) in many of our lakes may reflect a predation regime increasingly dominated by cyclopoid copepods.

Dominance of cyclopoid copepods and other small invertebrate predators in the lakes may be influenced by predation from acid-tolerant yellow perch (Perca flavescens), which consume cladocerans and invertebrate predators such as copepods and Chaoborus as part of their $\operatorname{diet}$ (Falk, 1971; Graeb et al., 2004). Due to its preference for larger prey items (e.g., size-selective predation), yellow perch predation can induce a shift towards smaller body size in its prey (Post and Cucin, 1984). Yellow perch is currently present in each of our lakes (with the exception of Lumsden Lake; Snucins and Gunn, 1998; City of Greater Sudbury, 2014), and its predation may have been responsible for the shift to smaller invertebrate predators (e.g., cyclopoid copepods) that was inferred from Bosmina size attributes. The absence of yellow perch in Lumsden Lake may explain why only minimal Bosmina size changes were observed. With the exception of Lumsden Lake (which remains fishless), the study lakes now contain between 4 - 11 fish species, including piscivorous smallmouth bass and northern pike (Snucins and Gunn, 1998; City of Greater Sudbury, 2014), suggesting that food web recovery is underway. However, despite a return of many fish species to the lakes, Bosmina size attributes have shown little evidence of recovery, indicating the persistence of altered food webs (Figs. 1-3).

In addition to shifts in predation regime, the alteration of food webs within the lakes may have impacted competition for food and resources. Bosmina was the dominant cladoceran species in each of our study lakes; however, the Sudbury study lakes experienced declines in cladoceran species richness (Yan et al., 2004; Labaj et al., 2015) and shifts in species composition as the lakes were contaminated. Notably, Chydorus brevilabris reached relative abundances of $15-70 \%$ in the Sudbury lakes during the period of contamination, and remained at relative abundances of $\sim 15$ and $30 \%$ in Clearwater and Daisy lakes, respectively (Labaj et al., 2015). In comparison, the Killarney lakes have experienced subtle increases in species richness, and minor $(<10 \%)$ increases in C. brevilabris through time (Labaj et al., 2015). Nonetheless,
Bosmina size attributes in George Lake (Killarney) show shifts of similar direction as the Sudbury lakes, suggesting that competition with other cladoceran species was not a prominent driver of Bosmina size structure.

During the recovery period, following a return of preimpact $\mathrm{pH}$ levels, size attributes largely continued to differ significantly from their pre-impact distributions in both Sudbury and Killarney lakes, and in many cases continued to shift further from their pre-impact distributions (Figs. 1-3). Climate change is expected to become increasingly important in structuring the biotic recovery of lakes (Keller, 2007; Labaj et al., 2015; Smol, 2010), further altering food webs that have not yet recovered from acidification. Within Sudbury, warming air temperatures in recent decades have been accompanied by increased surface mixed layer water temperature (Keller, 2007). Smaller organisms are predicted to be favoured under warmer conditions (Daufresne et al., 2009; Forster et al., 2012), and this may result in Bosmina with smaller size attributes in the future. Primary production in our study lakes has increased over the past $\sim 50$ years, likely linked to longer growing season and warmer water temperatures (Labaj et al., 2015). With increased primary production, Bosmina increase reproductive and growth rates, resulting in larger individuals (Goulden et al., 1982; Vanni, 1987). However, this relationship is unpredictable, and may be complicated by shifts in the timing of phytoplankton blooms, leading to an overall reduction of available food resources for zooplankton (Winder and Schindler, 2004), and consequently smaller individuals. Warmer water temperatures may also result in shifts to predation patterns, ultimately impacting Bosmina size structure. Specifically, predation by Chaoborus may intensify in warm isothermal waters, while decreasing in thermally stratified systems, due to the influences of temperature on Chaoborus metabolism (MacPhee et al., 2011; Labaj et al., 2013). Due to the unpredictable nature of thermal stratification under future climate scenarios (Keller, 2007), the impact of changing Chaoborus predation on Bosmina size structure is difficult to predict.

\section{CONCLUSIONS}

Our results suggest that the size structure of Bosmina communities changed significantly following the acidification of lakes in Sudbury and Killarney, with significant decreases in mucro length in four lakes and significant increases in carapace and antennule length in three lakes during the period of acidification. Despite the $\mathrm{pH}$ of each study lake having returned to pre-impact levels, bosminid size attributes remain significantly altered from their pre-impact distributions in many of the lakes. Similar changes in bosminid size structure occurred in both the Sudbury and Killarney regions, despite the vastly lower $\mathrm{Cu}$ and $\mathrm{Ni}$ levels in Killarney, suggesting that the size changes were not attributable to metal contamination. Instead the shifts in size 
structure were likely mediated by changes to food webs and predation regimes in response to decreasing $\mathrm{pH}$. The lack of a return to pre-impact Bosmina size distributions in many of the lakes suggests persistence of altered food webs. As these systems continue to recover, modern stressors such as climate change will become increasingly important in structuring biotic assemblages and size structure.

Acidification has led to the restructuring of aquatic food webs, which persists despite chemical recovery that has occurred in this region. We show that Bosmina size attributes preserved in lake sediments are responsive to changes in predator-prey dynamics that occur as a result of anthropogenic stressors. Furthermore, our results suggest that acidification and metal contamination impacted Bosmina sizes indirectly, through food web shifts, rather than through direct physiological effects. However, our results also show that the paradigm of larger appendages under invertebrate predation and smaller appendages under fish predation (Korosi et al., 2013) may be overly simplistic, as the size structure of invertebrate predators can lead to differences in bosminid morphology. Overall, the study of size attributes of Bosmina subfossils has the potential to provide important insights into the effects of acidification and other anthropogenic disturbances on aquatic food web structure in a long-term context.

\section{ACKNOWLEDGMENTS}

We wish to thank Joshua Thienpont for his assistance in the field, as well as the Cooperative Freshwater Ecology Unit for monitoring data from each of the study lakes. We also thank two anonymous reviewers who helped improve this manuscript with their constructive feedback. This research was funded by a Natural Sciences and Engineering Research Council of Canada (NSERC) grant to John Smol, and an NSERC graduate scholarship to Andrew Labaj.

\section{REFERENCES}

Appelberg M, Henrikson B, Henrikson L, Svedäng M, 1993. Biotic interactions within the littoral community of Swedish forest lakes during acidification. Ambio 22:290-297.

Appleby PG, 2001. Chronostratigraphic techniques in recent sediments, p. 171-203. In: W.M. Last and J.P. Smol (eds.), Tracking environmental change using lake sediments. 1. Basin analysis, coring, and chronological techniques. Springer.

Beamish RJ, Harvey HH, 1972. Acidification of the La Cloche Mountain lakes, Ontario, and resulting fish mortalities. J. Fish. Res. Board Can. 29:1131-1143.

Black AR, 1993. Predator-induced phenotypic plasticity in Daphnia pulex: life history and morphological responses to Nonecta and Chaoborus. Limnol. Oceanogr. 38:986-996.

Black RW, 1980. The nature and causes of cyclomorphosis in a species of the Bosmina longirostris complex. Ecology 61: 1122-1132.

Brahney J, Routledge R, Bos DG, Pellatt MG, 2010. Changes to the productivity and trophic structure of a sockeye salmon rearing lake in British Columbia. N. Am. J. Fish. Manage. 30:433-444.

Brooks JL, 1946. Cyclomorphosis in Daphnia: I. an analysis of D. retrocurva and D. galeata. Ecol. Monogr. 16:409-447.

City of Greater Sudbury, 2014. Fish species in local lakes. Available at: http://www.greatersudbury.ca/living/ lakes-facts/fishspecies-in-local-lakes/

Coker RE, 1939. The problem of cyclomorphosis in Daphnia. Q. Rev. Biol. 14:137-148.

Cooperative Freshwater Ecology Unit, Laurentian University, 2013. Sudbury and Killarney lake water chemistry monitoring data.

Daufresne M, Longfellner K, Sommer U, 2009. Global warming benefits the small in aquatic ecosystems. Proc. Natl. Acad. Sci. USA 106:12788-12793.

Deevey ES, Deevey GB, 1971. The American species of Eubosmina Seligo (Crustacea, Cladocera). Limnol. Oceanogr. 16:201-218.

DeMott WR, 1982. Feeding selectivities and relative ingestion rates of Daphnia and Bosmina. Limnol. Oceanogr. 27:518-527.

Dixit AS, Dixit SS, Evans RD, 1987. Paleolimnological evidence of recent acidification in two Sudbury (Canada) lakes. Sci. Total Environ. 67:53-67.

Dixit AS, Dixit SS, Smol JP, 1992. Algal microfossils provide high temporal resolution of environmental trends. Water Air Soil Poll. 62:75-87.

Dixit AS, Dixit SS, Smol JP, 1996. Setting restoration goals for an acid and metal-contaminated lake: a paleolimnological study of Daisy Lake (Sudbury, Canada). Lake Reserv. Manage. 12:323-330.

Dixit SS, Dixit AS, Smol JP, 1990. Paleolimnological investigation of three manipulated lakes from Sudbury, Canada. Hydrobiologia 214:245-252.

Falk MR, 1971. Food habits, gastric digestion and food consumption rates of yellow perch, Perca fluviatilis flavescens (Mitchill), in West Blue Lake, Manitoba. MSc Thesis, University of Manitoba, Winnipeg, Manitoba, Canada, 207 pp.

Forster J, Hirst AG, Atkinson D, 2012. Warming-induced reductions in body size are greater in aquatic than terrestrial species. Proc. Natl. Acad. Sci. USA 109: 19310-19314.

Glew JR, 1988. A portable extruding device for close interval sectioning of unconsolidated core samples. J. Paleolimnol. 1:235-239.

Glew JR, 1989. A new trigger mechanism for sediment samplers. J. Paleolimnol. 2:241- 243.

Goulden CE, Henry LL, Tessier AJ, 1982. Body size, energy reserves, and competitive ability in three species of Cladocera. Ecology 63:1780-1789.

Graeb BDS, Dettmers JM, 2004. Fish size and prey availability affect growth, survival, prey selection, and foraging behaviour of larval yellow perch. T. Am. Fish. Soc. 133:504-514.

Gunn JM, 1996. Restoring the smelter-damaged landscape near Sudbury, Canada. Restor. Manage. Notes 14:129-136.

Hart RC, Bychek EA, 2011. Body size in freshwater planktonic crustaceans: an overview of extrinsic determinants and modifying influences of biotic interactions. Hydrobiologia 668: 61-108.

Hebert PDN, 1978. Cyclomorphosis in natural populations of Daphnia cephalata King. Freshwater Biol. 8:79-90.

Hebert PDN, Grewe PM, 1985. Chaoborus-induced shifts in the 
morphology of Daphnia ambigua. Limnol. Oceanogr. 30:1291-1297.

Ingersoll CG, Winner RW, 1982. Effect on Daphnia pulex (De Greer) of daily pulse exposures to copper or cadmium. Environ. Toxicol. Chem. 1:321-327.

Kappes H, Sinsch U, 2002. Temperature- and predator-induced phenotypic plasticity in Bosmina cornuta and B. pellucida (Crustacea: Cladocera). Freshwater Biol. 47:1944-1955.

Keller W, 2007. Implications of climate warming for Boreal Shield lakes: a review and synthesis. Environ. Rev. 15:99-112.

Keller W, Heneberry J, Gunn JM, Snucins E, Morgan G, Leduc J, 2004. Recovery of acid and metal-damaged lakes near Sudbury Ontario: trends and status. Cooperative Freshwater Ecology Unit, Laurentian University, Sudbury, Ontario, 53 pp.

Kerfoot WC, 1975. The divergence of adjacent populations. Ecology 56:1298-1313.

Koivisto S, Ketola M, Walls M, 1992. Comparison of five cladoceran species in short- and long-term copper exposure. Hydrobiologia 248:125-136.

Korhola A, Rautio M, 2001. Cladocera and other brachiopod crustaceans, p. 5-41. In: J.P. Smol, H.J.B. Birks and W.M. Last (eds.), Tracking environmental change using lake sediments. 4. Zoological indicators. Springer, Dordrecht.

Korosi JB, Kurek J, Smol JP, 2013. A review on utilizing Bosmina size structure archived in lake sediments to infer historic shifts in predation regimes. J. Plankton Res. 35:444-460.

Korosi JB, Paterson AM, DeSellas AM, Smol JP, 2008. Linking mean body size of pelagic Cladocera to environmental variables in Precambrian Shield lakes: a paleolimnological approach. J. Limnol. 67:22-34.

Korosi JB, Paterson AM, DeSellas AM, Smol JP, 2010. A comparison of pre-industrial and present-day changes in Bosmina and Daphnia size structure from soft-water Ontario lakes. Can. J. Fish. Aquat. Sci. 67:754-762.

Labaj AL, Kurek J, Jeziorski A, Smol JP, 2015. Elevated metal concentrations inhibit biological recovery of Cladocera in previously acidified boreal lakes. Freshwater Biol. 60:347-359.

Labaj AL, Kurek J, Smol JP, 2014. Chaoborus americanus predation influences Bosmina mucro lengths in fishless lakes. J. Paleolimnol. 51:449-454.

Labaj AL, Kurek J, Weeber RC, Smol JP, 2013. Long-term changes in invertebrate size structure and composition in a boreal headwater lake with a known minnow introduction. J. Limnol. 72:215-226.

Lagergren R, Hellsten M, Stenson JAE, 1997. Increased drag, and thus lower speed: a cost for morphological defence in Bosmina (Eubosmina) (Crustacea: Cladocera). Funct. Ecol. 11:484-488.

Locke A, Sprules WG, 1993. Effects of experimental acidification on zooplankton population and community dynamics. Can. J. Fish. Aquat. Sci. 50:1238-1247.

Locke A, Sprules WG, 2000. Effects of acidic pH and phytoplankton on survival and condition of Bosmina longirostris and Daphnia pulex. Hydrobiologia 437:187-196.

Lynch M, 1977. Fitness and optimal body size in zooplankton population. Ecology 58:763-774.

MacPhee SA, Arnott SE, Keller W, 2011. Lake thermal structure influences macroinvertebrate predation on crustacean zooplankton. J. Plankton Res. 33:1586-1595.

Münzinger A, 1990. Effects of nickel on Daphnia magna during chronic exposure and alterations in the toxicity to generations pre-exposed to nickel. Water Res. 24:845-852.

Neary BP, Dillon PJ, Munro JR, Clark BJ, 1990. The acidification of Ontario lakes: an assessment of their sensitivity and current status with respect to biological damage. Ontario Ministry of the Environment, Dorset, Ontario, $171 \mathrm{pp.}$

Nilssen JP, Sandøy S, 1990. Recent lake acidification and cladoceran dynamics: surface sediment and core analyses from lakes in Norway, Scotland, and Sweden. P. Roy. Soc. B-Biol. Sci. 327:299-309.

Post DM, Frost TM, Kitchell JF, 1995. Morphological responses by Bosmina longirostris and Eubosmina tubicen to changes in copepod predator populations during a whole-lake acidification experiment. J. Plankton Res. 17:1621-1632.

Post JR, Cucin D, 1984. Changes in the benthic community of a small Precambrian lake following the introduction of yellow perch, Perca flavescens. Can. J. Fish. Aquat. Sci. 41:1496-1501.

Smol JP, 2010. The power of the past: using sediments to track the effects of multiple stressors on lake ecosystems. Freshwater Biol. 55 (Suppl.1):43-59.

Snetsinger R, 1993. Historic metal contamination of Sudbury area lake sediments. MSc Thesis, Queen's University, Kingston.

Snucins E, Gunn JM, 1998. Chemical and biological status of Killarney Park lakes (1995-1997). Cooperative Freshwater Ecology Unit, Laurentian University, Sudbury, Ontario, 175 pp.

Sprules WG, Carter JCH, Ramcharan CW, 1984. Phenotypic associations in the Bosminidae (Cladocera): zoogeographic patterns. Limnol. Oceanogr. 29:161-169.

Tóth LG, Kato K, 1997. Size-selective grazing of bacteria by Bosmina longirostris-an image-analysis study. J. Plankton Res. 19:1477-1493.

Tropea AE, 2008. Assessing biological recovery from acidification and metal contamination in urban lakes from Sudbury, Canada: a paleolimnological approach. MSc Thesis, Queen's University, Kingston, Ontario, Canada, 232 pp.

Tropea AE, Paterson AM, Keller W, Smol JP, 2010. Sudbury sediments revisited: evaluating limnological recovery in a multiple-stressor environment. Water Air Soil Poll. 210:317-333.

Valois AE, Keller W, Ramcharan CW, 2010. Abiotic and biotic processes in lakes recovering from acidification: the relative roles of metal toxicity and fish predation as barriers to zooplankton re-establishment. Freshwater Biol. 55:2585-2597.

Valois AE, Keller W, Ramcharan CW, 2011. Recovery in a multiple stressor environment: using the reference condition approach to examine zooplankton community change along opposing gradients. J. Plankton Res. 33:1417-1429.

Vanni MJ, 1987. Effects of food availability and fish predation on a zooplankton community. Ecol. Monogr. 57:61-68.

Winder M, Schindler DE, 2004. Climate change uncouples trophic interactions in an aquatic ecosystem. Ecology 85: 2100-2106.

Yan ND, Girard R, Heneberry JH, Keller W, Gunn JM, Dillon PJ, 2004. Recovery of copepod, but not cladoceran, zooplankton from severe and chronic effects of multiple stressors. Ecol. Lett. 7:452-460.

Yan ND, Keller W, MacIsaac HK, McEachern LJ, 1991. Regulation of zooplankton community structure of an acidified lake by Chaoborus. Ecol. Appl. 1:52-65.

Yan ND, Strus R, 1980. Crustacean zooplankton communities of acidic, metal-contaminated lakes near Sudbury, Ontario. Can. J. Fish. Aquat. Sci. 37:2282-2293. 